\title{
Balloon measurements of the vertical ionization profile over southern Israel and comparison to mid-latitude observations
}

Article

Accepted Version

Creative Commons: Attribution-Noncommercial-No Derivative Works 4.0

Yaniv, R., Yair, Y., Price, C., Nicoll, K., Harrison, G., Artamonov, A. and Usoskin, I. (2016) Balloon measurements of the vertical ionization profile over southern Israel and comparison to mid-latitude observations. Journal of Atmospheric and Solar-Terrestrial Physics, 149. pp. 87-92. ISSN 1364-6826 doi:

https://doi.org/10.1016/j.jastp.2016.10.003 Available at https://centaur.reading.ac.uk/67777/

It is advisable to refer to the publisher's version if you intend to cite from the work. See Guidance on citing.

Published version at: http://www.sciencedirect.com/science/article/pii/S1364682616303029

To link to this article DOI: http://dx.doi.org/10.1016/j.jastp.2016.10.003

Publisher: Elsevier

All outputs in CentAUR are protected by Intellectual Property Rights law, including copyright law. Copyright and IPR is retained by the creators or other copyright holders. Terms and conditions for use of this material are defined in the End User Agreement. 


\section{CentAUR}

Central Archive at the University of Reading

Reading's research outputs online 
1 Balloon measurements of the vertical ionization profile over

2 southern Israel and comparison to mid-latitude observations

3

4 Roy Yaniv $^{1}$, Yoav Yair $^{2}$, Colin Price $^{1}$, Keri Nicol $^{3}$, Giles Harrison ${ }^{3}$, Anton Artamonov ${ }^{4}$

5 and Ilya Usoskin ${ }^{4}$

6

$7 \quad{ }^{1}$ Department of Geosciences, Tel-Aviv University, Tel-Aviv, Israel.

$8{ }^{2}$ School of Sustainability, Interdisciplinary Center (IDC) Herzliya, Israel

$9{ }^{3}$ Department of Meteorology, University of Reading, United Kingdom.

$10{ }^{4}$ Space Climate group, Faculty of Science, University of Oulu, Finland. 


\section{Abstract}

Airborne measurements using meteorological balloons were conducted for the first

32 time from southern Israel (geographic $30^{\circ} 35^{\prime} \mathrm{N}, 34^{\circ} 45^{\prime} \mathrm{E}$ geomagnetic $27^{\circ} 6^{\prime} \mathrm{N} 112^{\circ} 23^{\prime} \mathrm{E}$ )

33 for measuring the vertical ionization profile during solar cycle 24 . The results show the

34 differences (increase of $\sim 30 \%$ ) in count rates as we proceed from solar maximum toward

35 solar minimum. The observed altitude of maximum ionization (the Regener-Pfotzer

36 maximum) was between $17-20 \mathrm{~km}$, and it agrees well with results from other

37 simultaneous measurements conducted at different latitudes (Reading, UK and Zaragoza-

38 Barcelona, Spain). When compared with predictions of an analytical model, we find a

39 highly significant correlation $\left(\mathrm{R}^{2}=0.97\right)$ between our observations and the computed

40 ionization profiles. The difference in count rates can be attributed to the height of the

41 tropopause due to the model using a US standard atmosphere that differs from the

42 measured atmospheric parameters above Israel.

\section{Introduction}

Over land and within the boundary layer (few hundred meters) the atmosphere is mostly ionized by radiation emitted from the decay of radioactive isotopes in the Earth's crust. Hess [1912] studied the ionization profile in the atmosphere and postulated that ionization should therefore decrease with altitude since the radioactive elements have a source near the surface. However, using balloon measurements Hess found that ionization increased at altitudes above $10 \mathrm{~km}$, and interpreted the results as caused by an external source, namely galactic cosmic rays (GCR). He claimed that the penetration depth of these particles was dependent on the energy spectrum of the incoming radiation [Hess 1912]. Regener extended Hess' measurements using balloons, reaching heights up to $20 \mathrm{~km}$ (Regener 1933). They found that the ionization from cosmic rays reaches its maximum value at altitudes between 17-24 km and is known as the Regener-Pfotzer maximum (RP max) and is geomagnetic-latitude dependent (Pfotzer 1936, Carlson and Watson 2014). Figure 1 shows past and present measurements of the ionization profile (counts $/ \mathrm{sec} / \mathrm{cm}^{2} /$ steradian) from a V-2 rocket up to $80 \mathrm{~km}$ at $40^{\circ}$ geomagnetic latitude, 
and a sounding balloon launch up to $30 \mathrm{~km}$ from Reading, UK with a ionization model fit overlaid. In both locations the RP max can be clearly observed [Israël 1970; Harrison et 61 al., 2014].

Up to $40 \mathrm{~km}$ above the surface the main ionization source in the atmosphere is GCR and, sporadically in the polar region, solar protons [Mironova et al., 2015]. Balloon measurements of charged particle fluxes $(>1 \mathrm{MeV})$ and ion production rates have been performed continuously from 1957 by the Lebedev Physics Institute, Russia [Bazilevskaya et al 2000, Bazilevskaya et al 2008]. They found a correlation between the ratio of ion production rate (q) and the cosmic charged particle flux (J) during days with no solar activity at polar latitudes given by: $\frac{q}{J}=A e^{-B H} \quad$ (where $\mathrm{A}=119.86 \mathrm{~cm}-1 ; \mathrm{B}=$ 0.148, and $\mathrm{H}$ is the altitude $[\mathrm{km}]$ - Bazilevskaya et al 2000 their Figure 4). The flux of cosmic rays reaching the atmosphere at any given location is a function of the energy spectrum, which is also impacted by solar activity, on short and long temporal scales and by the geomagnetic rigidity cutoff, effectively determined by the geomagnetic latitude. The rigidity is a key parameter for particle motion in magnetic fields and is defined as the particle's momentum over charge: particles cannot penetrate to locations where the geomagnetic cutoff is greater than the particle's rigidity (Bazilevskaya 2005, Smart et al 2006, Mironova et al., 2015).

Simultaneous ground and airborne measurements using a balloon equipped with an ionization counter (based on a Geiger tube) have previously been performed during quiet atmospheric conditions and during a solar flare event from Reading, UK [Nicoll and Harrison, 2014; Harrison et al., 2014]. During the solar flare, the X-ray burst was followed by a solar proton event that caused changes in the atmospheric electrical properties of the potential gradient and the conduction current at ground level, with an observed increase of more than $20 \%$ in the ionization at $20 \mathrm{~km}$, deduced from the RP max values that were measured relative to quiet conditions.

\section{Methodology}




\subsection{Instrumentation}

Measurements of the atmospheric ionization up to the height of $35 \mathrm{~km}$ were conducted using standard radiosonde balloons equipped with additional disposable ionization sensors developed by the University of Reading. The ionization sensor is composed of two LND714 miniature Geiger tubes which uses a microcontroller to count

92 the number of ionization events (the impact of a gamma photon counts as one event) that 93 occur within each tube per minute interval [Harrison et al., 2013]. Count rates reported 94 here are the mean count rate from both tubes. Each Geiger tube was calibrated by the 95 manufacturer using a Co-60 Ionization source with a gamma sensitivity of 1.5 96 (counts $\left.\mathrm{s}^{-1}\right) /\left(\mathrm{mR}\right.$ hour $\left.^{-1}\right)$ (Harrison et al., 2012; Harrison et al., 2013). The 97 ionization sensor is interfaced to a standard Vaisala RS92 radiosonde via the PANDORA 98 data acquisition system (Harrison et al, 2012).

The balloons were launched from the Wise Observatory in Mitzpe Ramon $\left(30^{\circ} 35^{\prime} \mathrm{N}, 34^{\circ} 45^{\prime} \mathrm{E}\right.$, altitude $850 \mathrm{~m}$ a.s.l.). This location is in an arid region of the southern part of Israel (the Negev highland desert) remote from Israel's major cities and other 102 sources of pollution. The area's climate typically exhibits hot and dry summers with 103 average daily temperature of $30{ }^{\circ} \mathrm{C}$ and cold winters with average temperature of $6{ }^{\circ} \mathrm{C}$. 104 These conditions readily facilitate other atmospheric electrical measurements (vertical E105 field, vertical conduction current, ELF and VLF), as described in Price and Melnikov 106 (2004), Elhalel et al. (2014) and Yaniv et al. (2016). We note that these are the first such

107 measurements ever conducted in Israel, and for that matter, in this low geomagnetic 108 latitude range. Thus, the measurements offer a much needed addition to the global map of 109 cosmic ray ionization, which is traditionally based on balloon measurements conducted at 110 mid and high-latitudes.

\subsection{Model Description}

We used the CRAC:CRII model of atmospheric ionization [Usoskin and 114 Kovaltsov, 2006; Usoskin et al., 2010], based on Monte Carlo calculations which 115 simulate the ionization by cosmic rays (interactions of particles (protons, alpha-particles 
116 and heavier species) and locally produced secondary particles (protons, electrons, 117 neutrons and muons)), enabling a comparison between observations and theoretical 118 predictions. The model output provides the vertical profile of the ion production rate and 119 is applicable to a US standard atmosphere. The predictions of the model have been 120 validated over a wide range of geographical latitudes and altitudes [Usoskin and 121 Kovaltsov 2006; Harrison et al 2014]. The model can assess the ionization rate by cosmic 122 rays, by considering the geomagnetic rigidity cutoff at the site and the actual cosmic ray 123 intensity as monitored by ground-based neutron monitors.

124 Atmospheric ionization is mostly defined by the flux of GCR outside the 125 atmosphere, which is modulated by solar activity: the GCR flux is greater for low solar 126 activity periods and visa versa. Solar modulation of GCR is often quantified via the 127 modulation potential [Usoskin et al., 2005]. Values of the modulation potential for the 128 days of the reported balloon flights are given in Table 1. One can see that the modulation 129 potential decreased in time between the launches, reflecting the declining phase of solar 130 activity in the present solar cycle.

\section{Results}

Six balloon launches were conducted during the period from October 2014 to June 2016 reaching altitudes of $\sim 18,29,28,34,35$ and $28 \mathrm{~km}$. Starting with launch \#3 we also used a parachute to measure parameters during descent. Table 1 summarizes the operational aspects of our airborne campaign including flight duration, peak pressure at the highest altitude, lowest temperature measured during the flight and the highest count rate representing the RP max altitude. Figure 2 shows the flight trajectories on a regional map, indicating that some balloons drifted with the stratospheric winds to Jordan and 140 Egypt, and were thus not retrievable.

141 Figures $3 \mathrm{a}, 3 \mathrm{~b}$ and $3 \mathrm{c}$ present the vertical profiles of the temperature, pressure and 142 relative humidity respectively showing the meteorological conditions for each launch. 143 Figures $3 \mathrm{a}$ and $3 \mathrm{~b}$ also show temperature and pressure from the U.S. Standard 
144 Atmosphere 1976, (NASA-TM-X-74335), which agree well with the sounding profiles, 145 although some differences can be clearly noted, as we will discuss later on.

146 Figure 4a shows the count rates of the Geiger counters as a function of altitude for 147 each launch and the mean calculated ionization curve (black line) which peaks in the 148 height range of $17-20 \mathrm{~km}$. According to the 1976 US standard atmosphere values 149 (http://www.digitaldutch.com/atmoscalc/), the height range of 17-20 km measured in the 150 mean ionization curve corresponds to the pressure of 100 mbar as shown in Fig. $4 \mathrm{~b}$. 151 Figure $4 \mathrm{~b}$ is a fit of the count rate versus the measured atmospheric pressure and is in 152 agreement with Fig. 1b. Figure 4b shows that from 2014 to 2016 the ionization value had 153 steadily increased by $\sim 30 \%$.

154 Bazilevskaya (2014) noted an impact of the solar cycle on the flux of GCR 155 arriving to Earth's atmosphere. Maximum solar activity diminishes the flux of GCR 156 while minimum activity increases the flux of GCR. Figure 5 shows the negative linear 157 correlation between the RP max counts per minute and the modulation potential. Flight 158 \#4 (27 Aug 2015) was conducted during an M class solar flare event with $\mathrm{Kp}=7$ while 159 flight \#5 was conducted in fair weather on a quiet solar day.

160 The second launch was conducted simultaneously with other launches at various 161 locations in order to compare the vertical ionization profiles at different geomagnetic 162 latitudes during 22 $2^{\text {nd }}-24$ th October 2014 (Makhmutov et al., 2015). Figure 6 shows the 163 fit of the ionization profile as was measured by ionization sensors from Mitzpe Ramon 164 (Israel), Zaragoza-Barcelona (Spain) and Reading (UK). We can clearly see the 165 differences in the RP maximum altitude and the count rate as a function of the 166 geomagnetic latitudes. The Reading flight shows a higher count rate, followed by 167 Zaragoza-Barcelona measurement while the Israeli flight shows the lowest count rate. 168 Figure 7 presents the CRAC:CRII model results of the ion production rate as a function 169 of height for the Israel-Spain-UK balloon flights. We used the model to simulate the 170 ionization rate in the atmosphere as a function of the geomagnetic latitudes for the 171 simultaneous launches conducted from Israel, Spain and the UK during 22-24 Oct 2014. 172 Harrison et al., (2014) used a factor of 2.95 for a standard atmosphere to convert the 
173 ionization count rates (in counts $\min ^{-1}$ ) to ion production rates. Using this conversion 174 coefficient we found a good correlations $\left(\mathrm{R}^{2}>0.9\right)$ between the actual measurement from 175 Israel and the model from the 22 Oct 2014 (Figure 8 top) and the 14 May 2015 launch 176 (Figure8 bottom).

\section{Discussion}

We present results of airborne measurement conducted for the first time above Israel and from a low latitude location, adding new information on the latitudinal 181 dependence of cosmic ray induced ionization, and complementing the majority of airborne measurements that were performed at mid and high latitudes over Europe, 183 Russia and the US.

184 The difference (10-35\% lower) in the meteorological parameters shown in figure $1853 \mathrm{a}$ and $3 \mathrm{~b}$ compared with the U.S standard atmosphere model is especially pronounced in 186 the temperature profile near the tropopause. As discussed below, this US Standard 187 Atmosphere, when used in the CRAC:CRII model, is the main reason for differences 188 between our observations and the model results. Figure $3 \mathrm{c}$ also shows large variability in the vertical profile of the relative humidity, indicating periods when the balloon ascended through layers of visible clouds. We visually observed and identified the relevant cloud 191 types, as indicted in the graphs.

\subsection{Solar activity impact on ionization:}

The ionization increase shown in Figure $4 \mathrm{a}$ and Figure $4 \mathrm{~b}$ results from the overall 194 increase of the GCR flux impacting the Earth due to a decrease in the activity of the sun 195 reflecting the declining phase of solar cycle 24. Table 1 shows values of the modulation 196 potential (cosmic ray modulation parameter deduced from the sunspot index (Nymmik et 197 al., 1996). It is clearly evident from Figure 5 that ionization count rates increase from $~ 30$ $198 \mathrm{cpm}$ to $\sim 50 \mathrm{cpm}$ as the modulation potential decreases, as more GCR penetrate into the 199 Earth's atmosphere indicating that the sun is approaching solar minimum. During a solar 200 event that occurred during the launch of 27 Aug 2015 (Kp 7), we observed no impact on 201 the ionization profile, likely because of the high cutoff rigidity at the latitude of Israel. 
202 We can conclude that short term variations are too small to be recorded using our 203 instrument, but long term variations in solar activity can be monitored. Similar results 204 were found by Harrison (2014) during the rising phase of solar cycle 24 toward solar 205 maximum with ionization values of the RP max decreasing from around $80 \mathrm{cpm}$ in 2013 206 to $60 \mathrm{cpm}$ in 2014.

\subsection{Geomagnetic latitude effect on ionization:}

The differences found between the ionization values from Israel, Spain and the

210 GCR particles by the magnetosphere at the lower latitude of Israel). While high and mid-

211 latitude measurements of the vertical ionization profile are quite abundant [Nicoll 2012],

212 results in low-latitudes and sub-tropical regions are quite rare, and none have been 213 reported in the geomagnetic latitude of Israel $(\sim 27 \mathrm{~N})$ where the cutoff rigidity is $10.3 \mathrm{GV}$ 214 (compared to Spain 4.6GV and the UK 3.6GV). It is observable that the altitude of the 215 RP max at all locations is in good agreement while the intensity of the GCR penetrating 216 decrease as we proceed from polar to equatorial latitudes - values ranged around 25, 40 217 and $50 \mathrm{cpm}$ for Israel, Spain and UK respectively. Measurements in polar latitudes 218 (Mirny, Antarctica (geomagnetic latitude 67.23 S) with cutoff rigidity of $0.03 \mathrm{GV}$ and 219 Apatity, Russia (geomagnetic latitude $68.14 \mathrm{~N}$ ) with cutoff rigidity of $0.56 \mathrm{GV}$ ) obtained 220 by Makhmutuv et al (2014) on the same day but with a different instrument found higher 221 ionization values than the UK.

222 The model results shown in Figure 7 agree well with the simultaneous 223 measurements showing that ion production rates (ion pairs $/ \mathrm{cm}^{3} / \mathrm{s}$ ) are larger at higher 224 latitudes where the cutoff rigidity is smaller and lower at lower latitudes where the cutoff 225 rigidity is greater, thus, confirming the results presented in Figure 6. Model results for 226 other balloon flights were in good agreement as well while the small differences are 227 likely due to the use of the Standard US atmosphere in the model rather than the actual 228 atmospheric density profiles from the balloon measurements. 


\section{Summary}

Balloon measurements of the vertical ionization profile have been conducted for

232 the first time in Israel. We found that the Regener-Pfotzer maximum to be in the expected 233 altitude range of $17-20 \mathrm{~km}$ at an atmospheric pressure of $\sim 100 \mathrm{mbar}$. The effect of the

234 present phase of solar cycle 24 is clearly evident in the measured ionization count rates 235 showing an increase in ionization due to increases in GCR fluxes as expected from the 236 declining phase toward the next solar minimum. Simultaneous measurements from 237 different latitudes using the same Geiger counters found a latitudinal dependence of the 238 count rates as expected - higher count rates $(\sim 50 \mathrm{cpm})$ for the mid-latitudes of Spain and 239 UK where the geomagnetic rigidity is lower compared to the low latitude of Israel $(\sim 25$ $240 \mathrm{cpm})$. Model calculations of ion pair-production rate profile were found to correlate 241 positively $\left(\mathrm{R}^{2}>0.9\right)$ with the measurements.

\section{Acknowledgments}

244 This research is supported by the Israel Science Foundation (grant No. 423/13).

245 The work of A.A. and I.U. was done in the framework of ReSoLVE Centre of Excellence 246 (Academy of Finland, project 272157).

247 The ionization sensor developed under STFC grant ST/K001965/1. KAN acknowledges 248 an early Career fellowship of the Leverhulme Trust (ECF-2011-225) and NERC 249 Independent Research Fellowship (NE/L011514/1).

\section{References:}

252 Bartlett, D.T., Tommasino, L., Beck, P., Wissmann, F., O’Sullivan D., Bottollier-Depois, 253 J.-F. and Lindborg L. Investigation of Radiation Doses at Aircraft Altitudes during a 254 Complete Solar Cycle: DOSMAX-A collaborative Research Program. Presented at the 255 12th Biennial Topical Meeting at XXX 2002.

256 Bazilevskaya G.A., Krainev M.B., Makhmutov V.S., Effects of cosmic rays on the 257 earth’s environment, J. Atmos. Sol.-Terr. Phys. 62, 1577-1586, 2000. 
Bazilevskaya G.A., Solar cosmic rays in the near Earth space and the atmosphere. Adv. Space Res. 35, 458-464, 2005.

Bazilevskaya G.A., Usoskin I.G., Flückiger E.O., Harrison R.G., Desorgher L., Bütikofer R., Krainev M.B., Makhmutov V.S., Stozhkov Y.I., Svirzhevskaya A.K., Svirzhevsky N.S., Kovaltsov G.A., Cosmic ray induced ion production in the atmosphere. Space Sci. Rev. 137, 149-173, 2008.

Bazilevskaya, G. A., Cliver, E. W., Kovaltsov, G. A., Ling, A. G., Shea, M. A., Smart, D. F., \& Usoskin, I. G., Solar cycle in the heliosphere and cosmic rays. Space Science

Reviews, 186(1-4), 409-435, 2014.

Carlson, P., \& Watson, A. A. (2014). Erich Regener and the ionization maximum of the atmosphere. History of Geo-and Space Sciences, 5(2), 175.

Elhalel G., Yair Y., Nicoll K., Price C., Reuveni Y., and Harrison R. G., Influence of short-term solar disturbances on the fair weather conduction current, J. Space Weather Space Clim. 4, A26 DOI: 10.1051, 2014.

Friedberg, W., Copeland, K., Duke, F. E., O'Brien III, K., \& Darden Jr, E. B. Guidelines and technical information provided by the US Federal Aviation Administration to promote radiation safety for air carrier crew members. Radiation Protection Dosimetry, 86(4), 323-327, 1999.

Harrison, R. G., Nicoll, K. A., Lomas A. G., Programmable data acquisition system for research measurements from meteorological radiosondes, Rev. Sci. Instrum., 83, 036106, 2012.

Harrison, R. G., Nicoll, K. A., Lomas A. G., Geiger tube coincidence counter for lower atmosphere radiosonde measurements, Rev. Sci. Instrum., 84, 076103, 2013.

Harrison, R. G., Nicoll, K. A., Aplin, K. L., Vertical profile measurements of lower troposphere ionization. Journal of Atmospheric and Solar-Terrestrial Physics, 119, 203-210., 2014.

Hess V. F., Über beobachtungen der durchdringenden Strahlung bei sieben Freiballonfahrten, Zeitschrift fur Physik, vol. 13, pp. 1084-1091, 1912. 
Israël, H. Atmospheric electricity: Atmosphärische Elektrizität. Vol. 29. Israel Program for Scientific Translations [available from the US Dept. of Commerce, National Technical Information Service, Springfield, Va.(Jerusalem), 1970.

Makhmutov, V., Bazilevskaya, G., Stozhkov, Y., Philippov, M., Yair, Y., Yaniv, R., Harrison G., Nicoll K. and Aplin, K. Cosmic ray measurements in the atmosphere at several latitudes in October, 2014, Proceeding of Science, ICRC 2015.

Mishev, Alexander, and Ilya Usoskin, Numerical model for computation of effective and ambient dose equivalent at flight altitudes-Application for dose assessment during GLEs, Journal of Space Weather and Space Climate 5, 2015.

Mironova, I. A., Aplin, K. L., Arnold, F., Bazilevskaya, G. A., Harrison, R. G., Krivolutsky, A. A., Nicoll K. A., Rozanov E. V., Turunen E. \& Usoskin, I. G., Energetic Particle Influence on the Earth's Atmosphere. Space Science Reviews, 194(1-4), 1-96, 2015.

Nicoll, K. A. "Measurements of atmospheric electricity aloft." Surveys in geophysics 33.5, 991-1057, 2012.

Nicoll, K. A., Harrison, R. G., Detection of lower tropospheric responses to solar energetic particles at midlatitudes. Physical review letters, 112(22), 225001, 2014.

Nymmik R.A., Panasyuk M.I. et Suslov A.A., Adv. Space Research, 17, (2)19-(2)30, 1996.

Pfotzer, G., Dreifachkoinzidenzen der Ultrastrahlung aus vertikaler Richtung in der Stratosphare, II, Analyse der gemessenen Kurve, Z. Phys., 102, 41-58, 1936 b.

Price, C., and A. Melnikov, Diurnal, Seasonal and Inter-annual Variations in the Schumann Resonance Parameters, Journal of Atmospheric and Solar-Terrestrial Physics, 66, 1179-1185, 2004.

Regener, E.: New Results in Cosmic Ray Measurements, Nature, 132, 696-698, 1933.

Smart, D.F., M.A. Shea, A.J. Tylka, P.R. Boberg, A geomagnetic cutoff rigidity 313 interpolation tool: Accuracy verification and application to space weather. Adv. Space Res. 37, 1206-1217, 2006. 
314 Usoskin, I.G., K. Alanko-Huotari, G.A. Kovaltsov, K. Mursula, Heliospheric modulation

315 of cosmic rays: Monthly reconstruction for 1951-2004, J. Geophys. Res., 110(A12), 316 CiteID A12108, 2005.

317 Usoskin I., Kovaltsov G., Cosmic ray induced ionization in the atmosphere: Full 318 modeling and practical applications, Journal of geophysical research 11, D21206, 3192006.

320 Usoskin, I. G., G. A. Kovaltsov, and I. A. Mironova, Cosmic ray induced ionization 321 model CRAC:CRII: An extension to the upper atmosphere, J. Geophys. Res., 115, 322 D10302, 2010.

323 Yaniv, R., Yair, Y., Price, C., \& Katz, S., Local and global impacts on the fair-weather 324 electric field in Israel. Atmospheric Research, Vol 172-173, p. 119-125, 2016.

327 Figure Captions:

328 Figure 1. Ionization-altitude curves of ionization from cosmic radiation. (left) past rocket launch [adapted 329 from Israël 1970 his figure 26] and (right) modern balloon launch. [adapted from Harrison et al 2014]

Figure 2. Regional map of Israel and surrounding countries with flight trajectories for each launch.

Figure 3. Vertical temperature profile (a), pressure profile (b) and relative humidity profile (c) for each launch. We note the locations of several cloud types, based on the RH values and visual observations.

Figure 4. Ionization variation versus the altitude $[\mathrm{km}]$ (a) and Vertical Ionization profile [counts mins ${ }^{-1}$, cpm] versus the Pressure [mbar] (b). The black line shows the average value of 6 launches

Figure 5. Modulation potential as a function of the Ionization count rate shows the effect of Solar cycle 24 phase on the Ionization in low latitudes.

342 Figure 6. Ionization curves from Mitzpe Ramon (Israel), Zaragoza-Barcelona (Spain) and Reading (UK). 
344 Figure 7. Model results of Ion production rate versus altitude from Mitzpe Ramon (Israel), -Barcelona

345 (Spain) and Reading (UK) of the 14 May 2015 Balloon launch.

346

347 Figure 8. Observations and modelled ion production rates (top) 14 May 2015 flight and (bottom) 22 Oct

3482014 flight.

349

350 Table Captions

351

352 Table 1. Summary of balloon launches. (*) Ascent only.

\begin{tabular}{|c|c|c|c|c|c|c|c|}
\hline Launch & Date & $\begin{array}{c}\text { Modulation } \\
\text { potential } \\
{[\mathrm{MV}]}\end{array}$ & $\begin{array}{c}\text { Flight } \\
\text { Duration [s] }\end{array}$ & $\begin{array}{c}\text { Peak } \\
\text { Altitude [m] }\end{array}$ & $\begin{array}{c}\text { Pressure } \\
\text { [mbar] } \\
\text { at peak }\end{array}$ & $\begin{array}{c}\text { Lowest } \\
\text { Temperature } \\
{\left[{ }^{\circ} \mathrm{C}\right] \text { recorded }}\end{array}$ & $\begin{array}{c}\text { (RP max) } \\
\text { cpm @ [km] }\end{array}$ \\
\hline $1 *$ & $\begin{array}{l}6 \text { Oct } \\
2014\end{array}$ & 677 & 3149 & 17542 & 85.5 & $\begin{array}{c}-72.3 @ 16.3 \\
\text { km }\end{array}$ & $\begin{array}{c}28.1 \mathrm{cpm} \text { at } \\
16.2 \mathrm{~km}\end{array}$ \\
\hline $2 *$ & $\begin{array}{c}22 \text { Oct } \\
2014\end{array}$ & 621 & 5342 & 29467 & 12.6 & $\begin{array}{c}\text {-74.7@17.2 } \\
\text { km }\end{array}$ & $\begin{array}{c}36.1 \mathrm{cpm} \text { at } \\
18.5 \mathrm{~km}\end{array}$ \\
\hline 3 & $\begin{array}{c}14 \\
\text { May } \\
2015\end{array}$ & 656 & 6325 & 28320 & 15.2 & $\begin{array}{c}-63.9 @ 20.2 \\
k m\end{array}$ & $\begin{array}{c}31.3 \mathrm{cpm} \text { at } \\
16.07 \mathrm{~km}\end{array}$ \\
\hline 4 & $\begin{array}{c}27 \text { Aug } \\
2015\end{array}$ & 573 & 9351 & 34796 & 6.1 & $\begin{array}{c}-74 @ 16.7 \\
\text { km }\end{array}$ & $\begin{array}{c}40.80 \mathrm{cpm} \text { at } \\
21.8 \mathrm{~km}\end{array}$ \\
\hline $5 *$ & $\begin{array}{c}20 \text { Jun } \\
2016\end{array}$ & 449 & 6431 & 35496 & 5.4 & $\begin{array}{c}-74.5 @ 17.5 \\
\text { km }\end{array}$ & $\begin{array}{c}50.87 \mathrm{cpm} \text { at } \\
17.1 \mathrm{~km}\end{array}$ \\
\hline $6^{*}$ & $\begin{array}{c}30 \text { Aug } \\
2016\end{array}$ & 337 & 7639 & 28200 & 16.67 & $\begin{array}{c}\text {-80.7@ } 17.6 \\
\text { km }\end{array}$ & $\begin{array}{c}47.1 \mathrm{cpm} \text { at } \\
19 \mathrm{~km}\end{array}$ \\
\hline
\end{tabular}


359 Figures:

360 Figure 1:

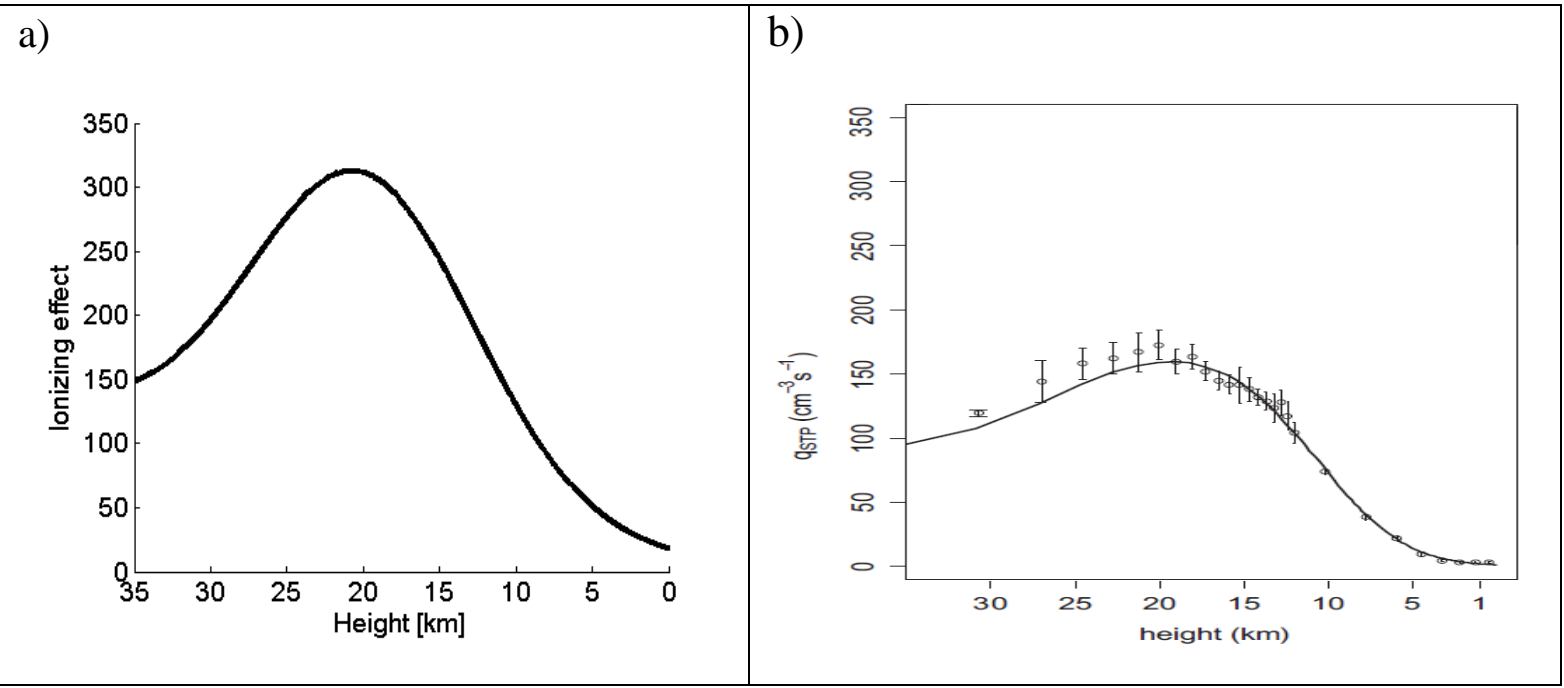

361

362 Figure 2:

363 


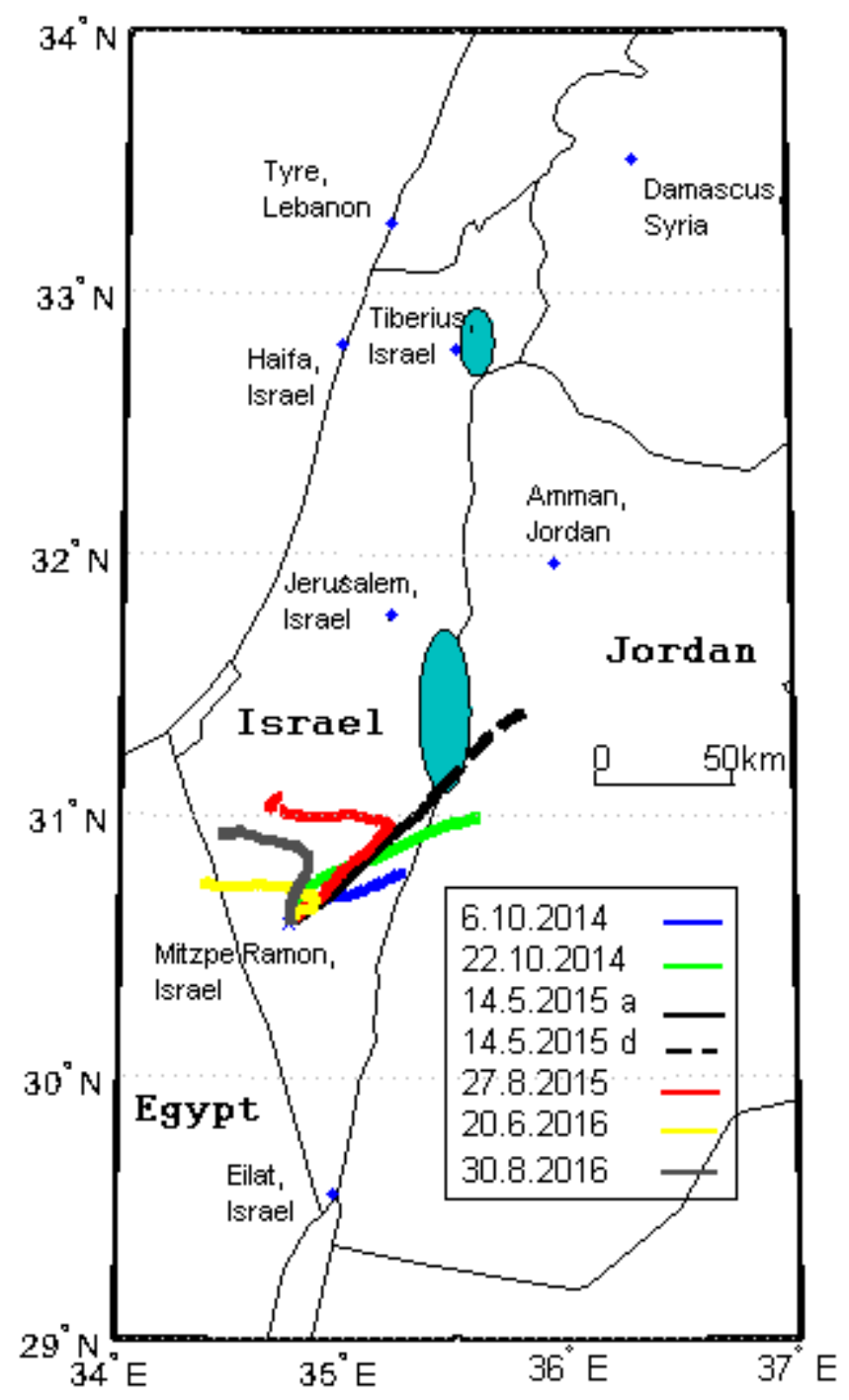

364

365

366

367 
Figure 3:

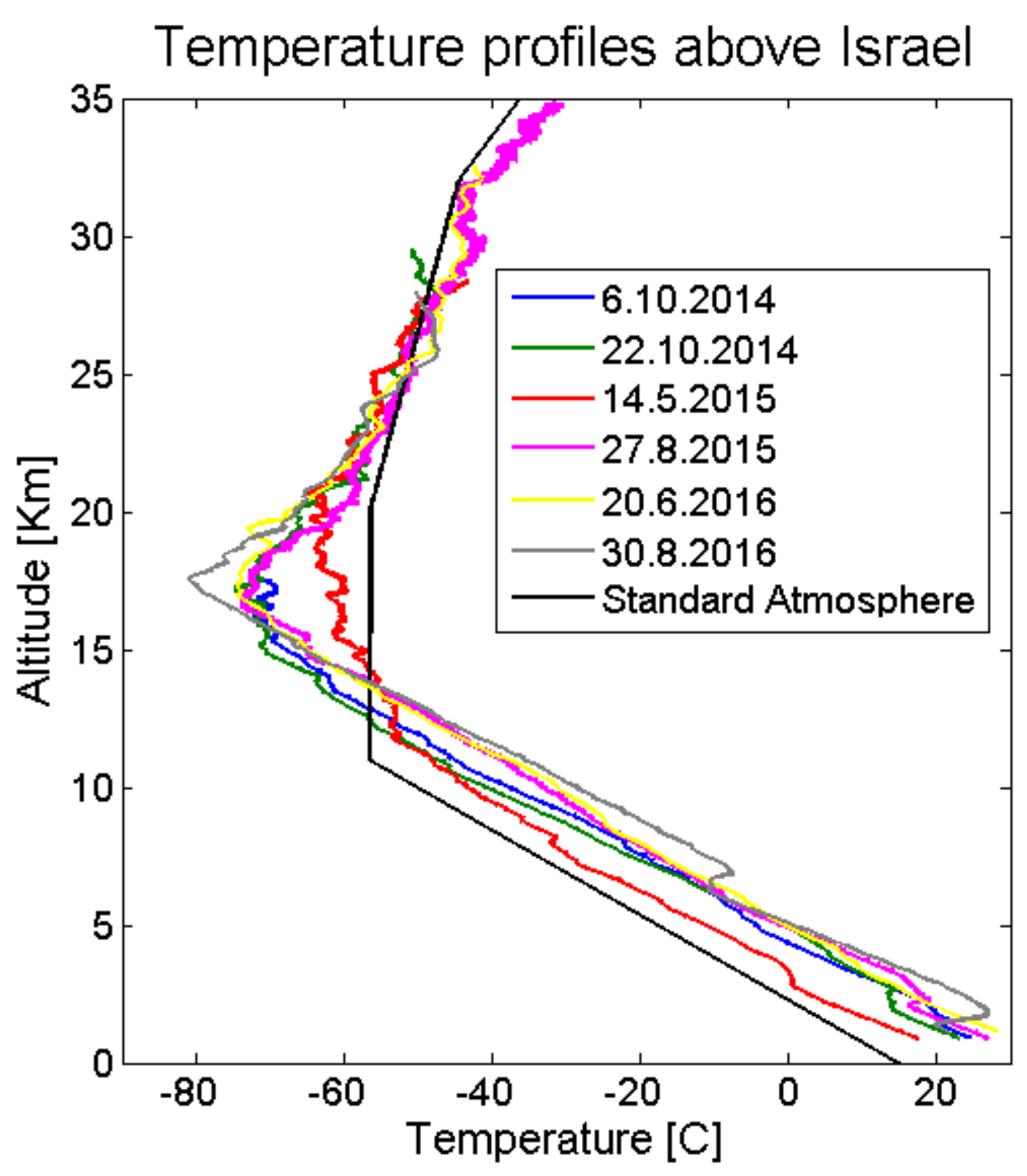

a)

b) 


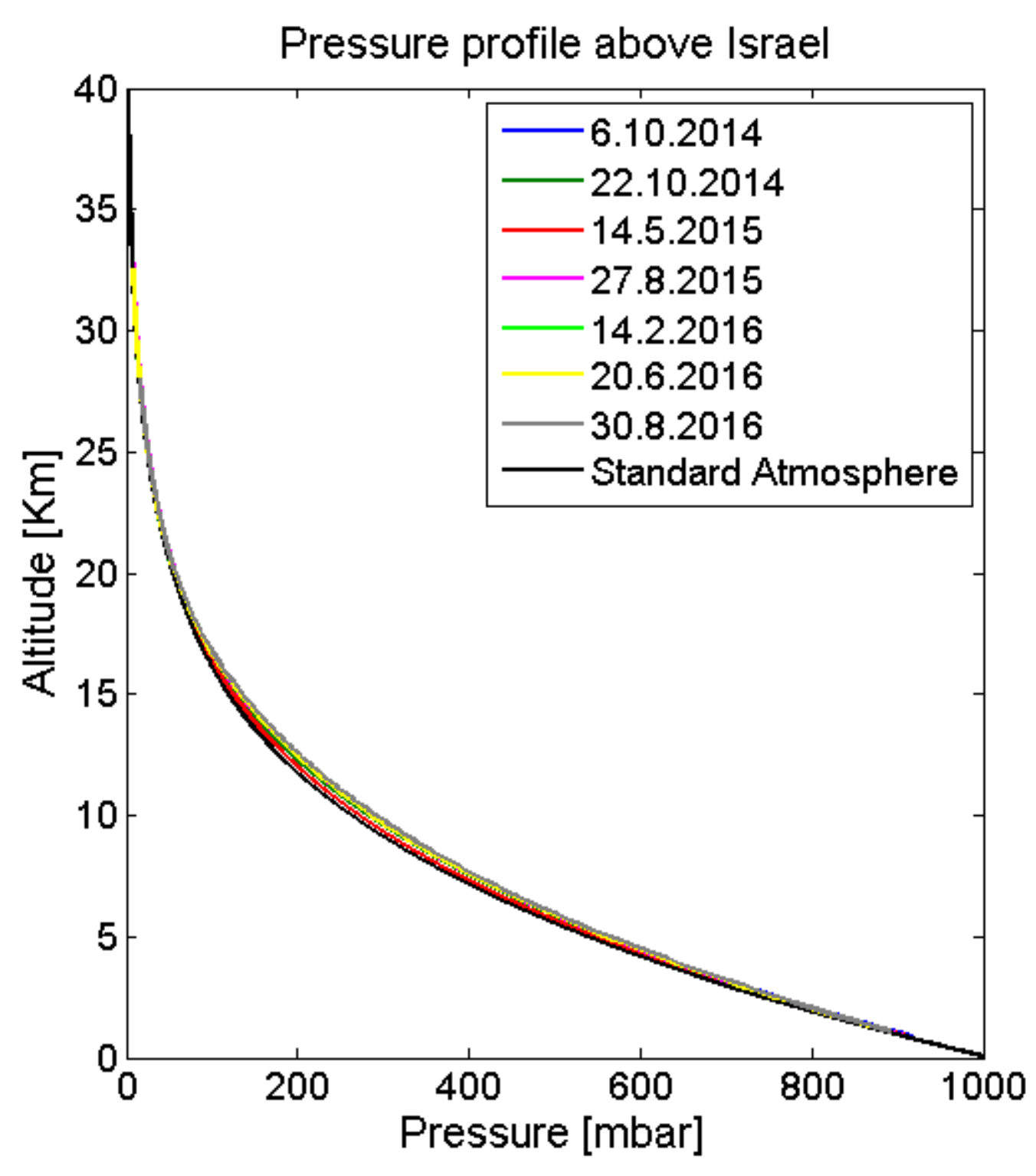

c) 


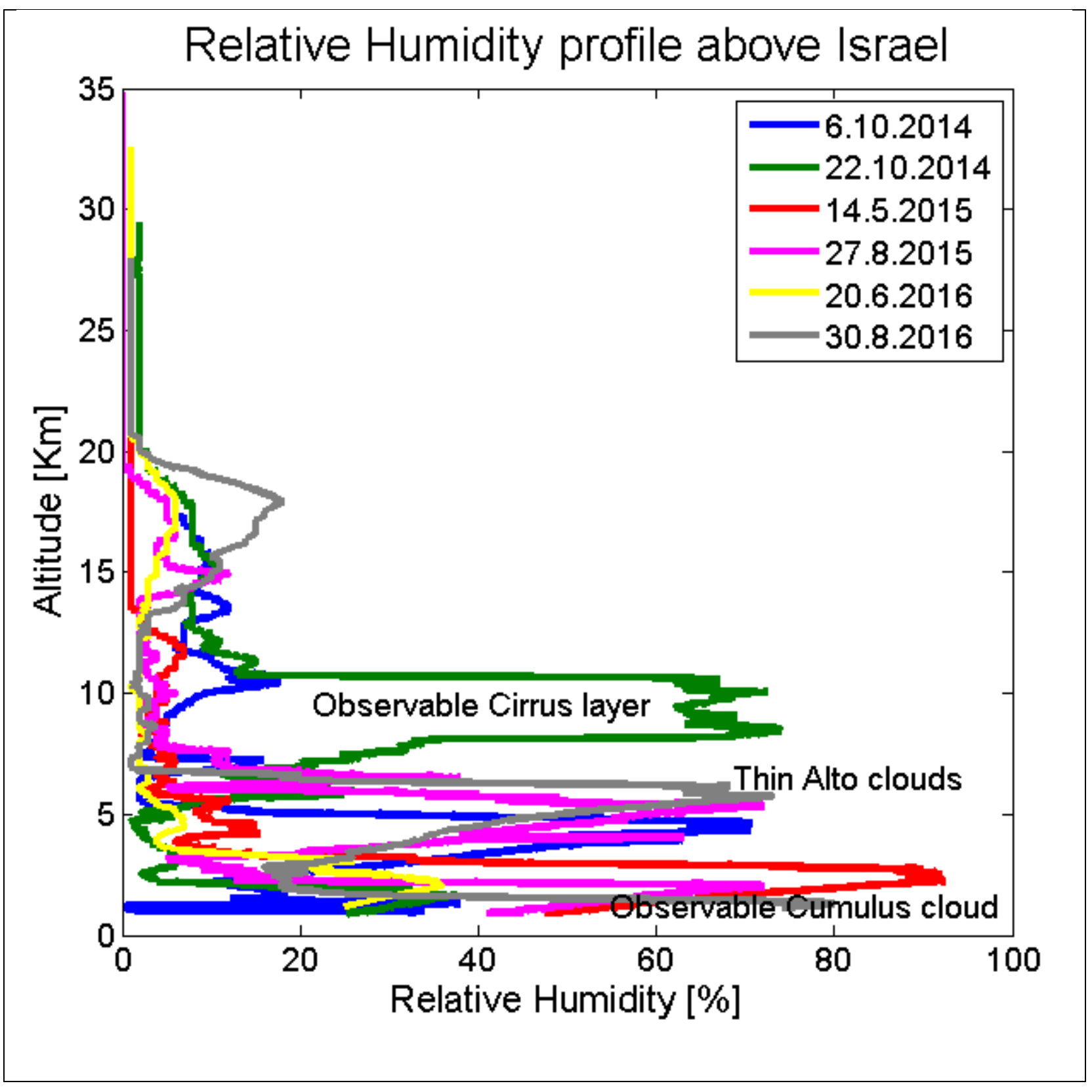




\section{$377 \quad$ Figure 4:}

a)

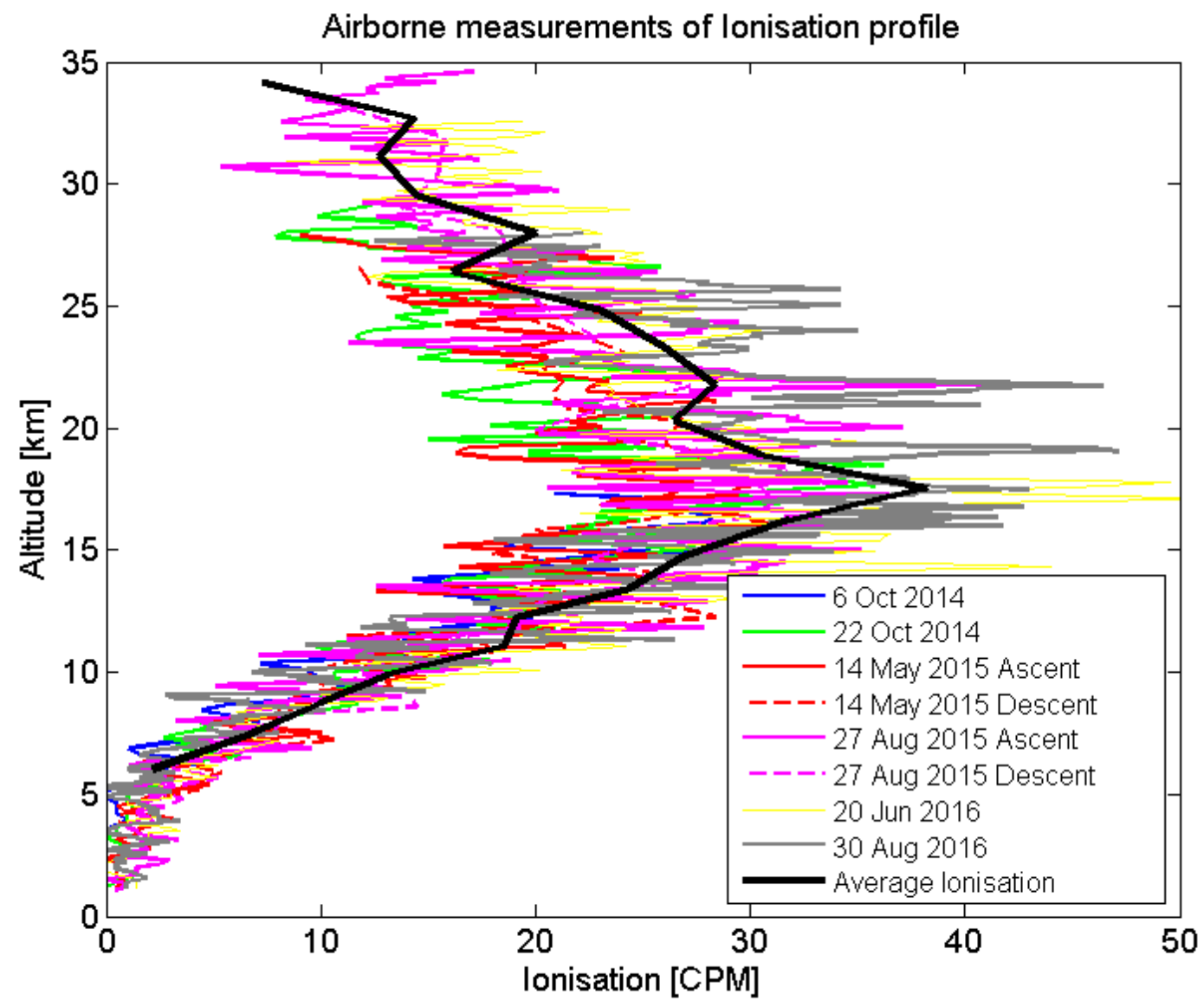

b) 


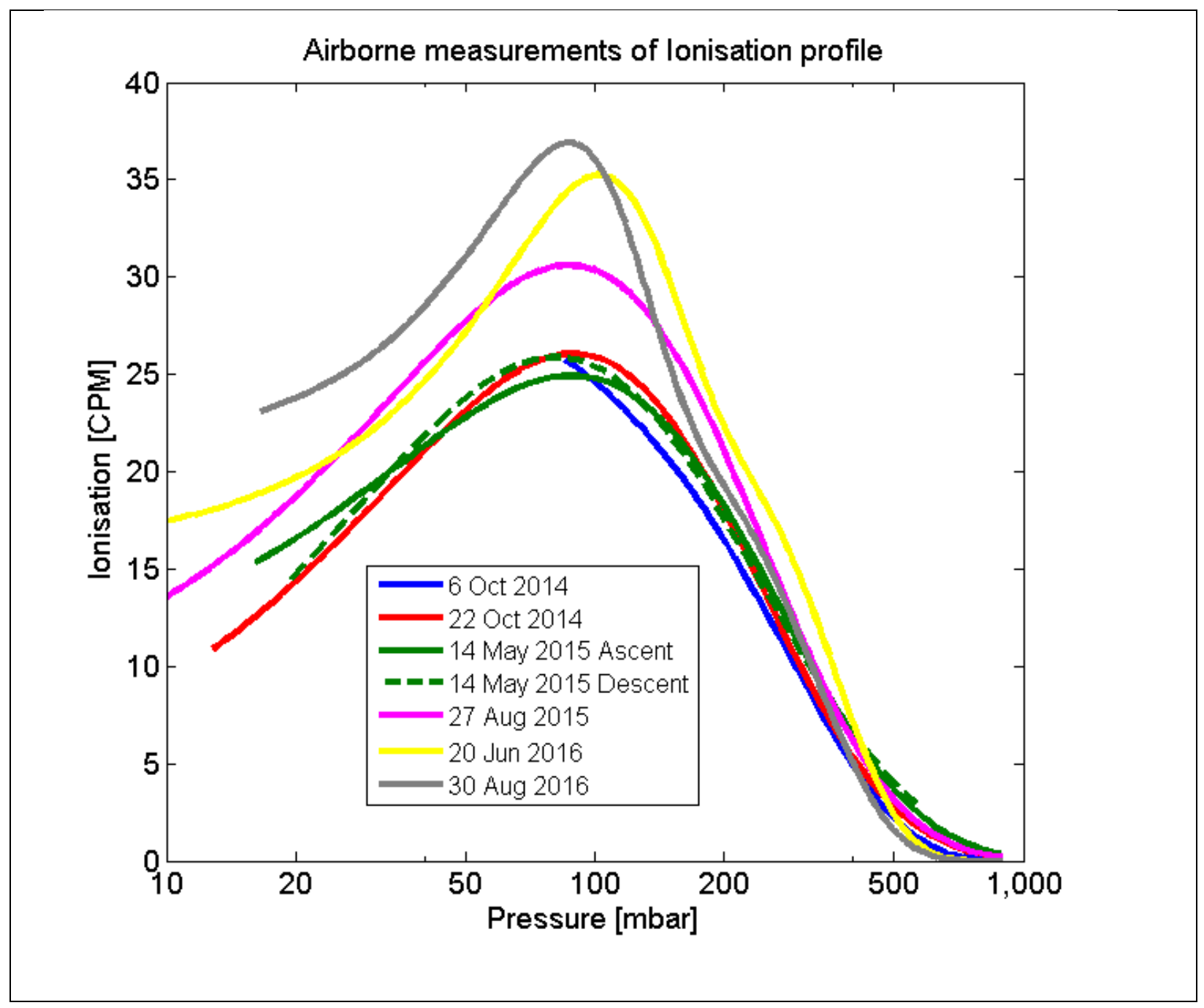

Figure 5: 


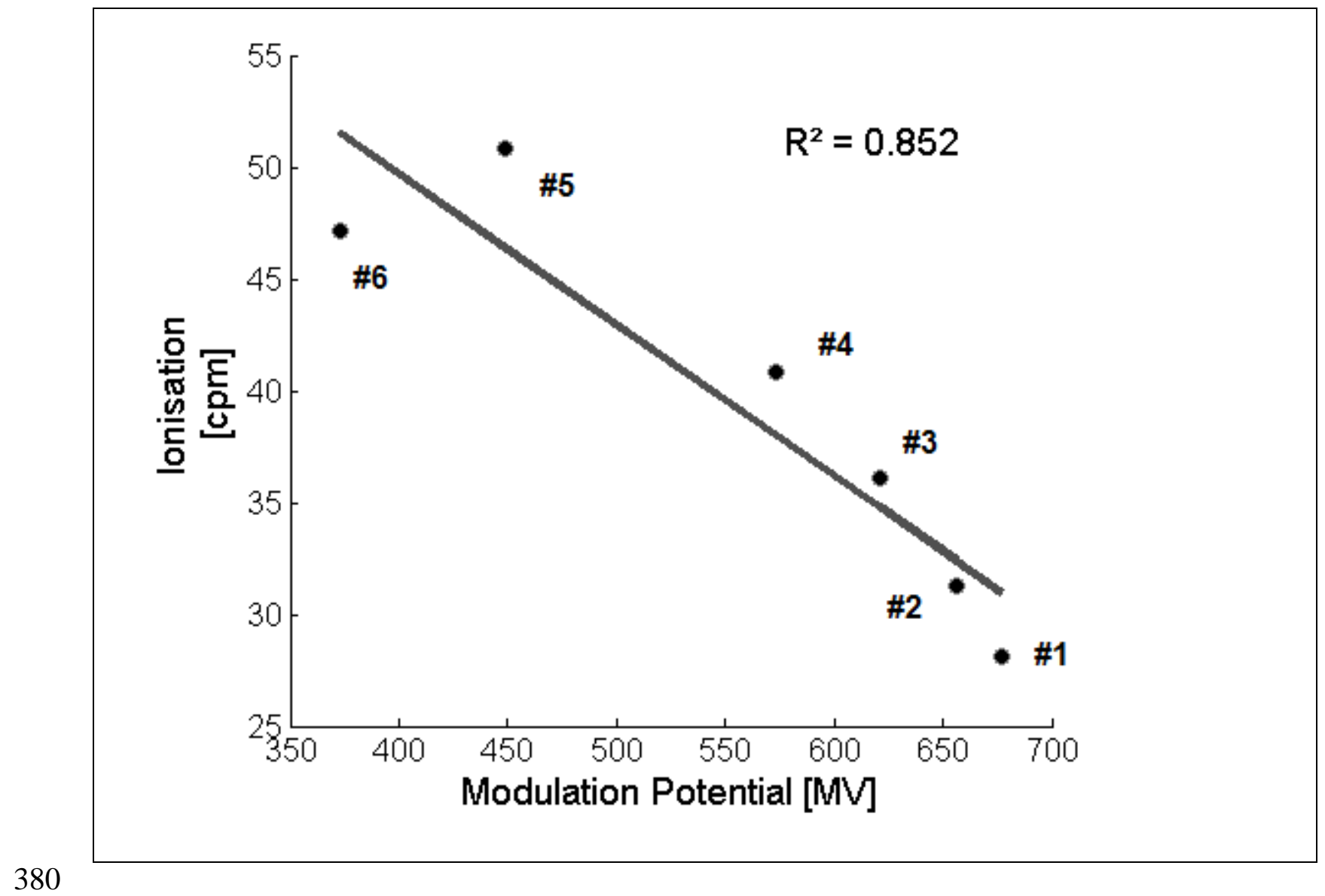

381

382

383

384

385

386

387

388

389 Figure 6: 


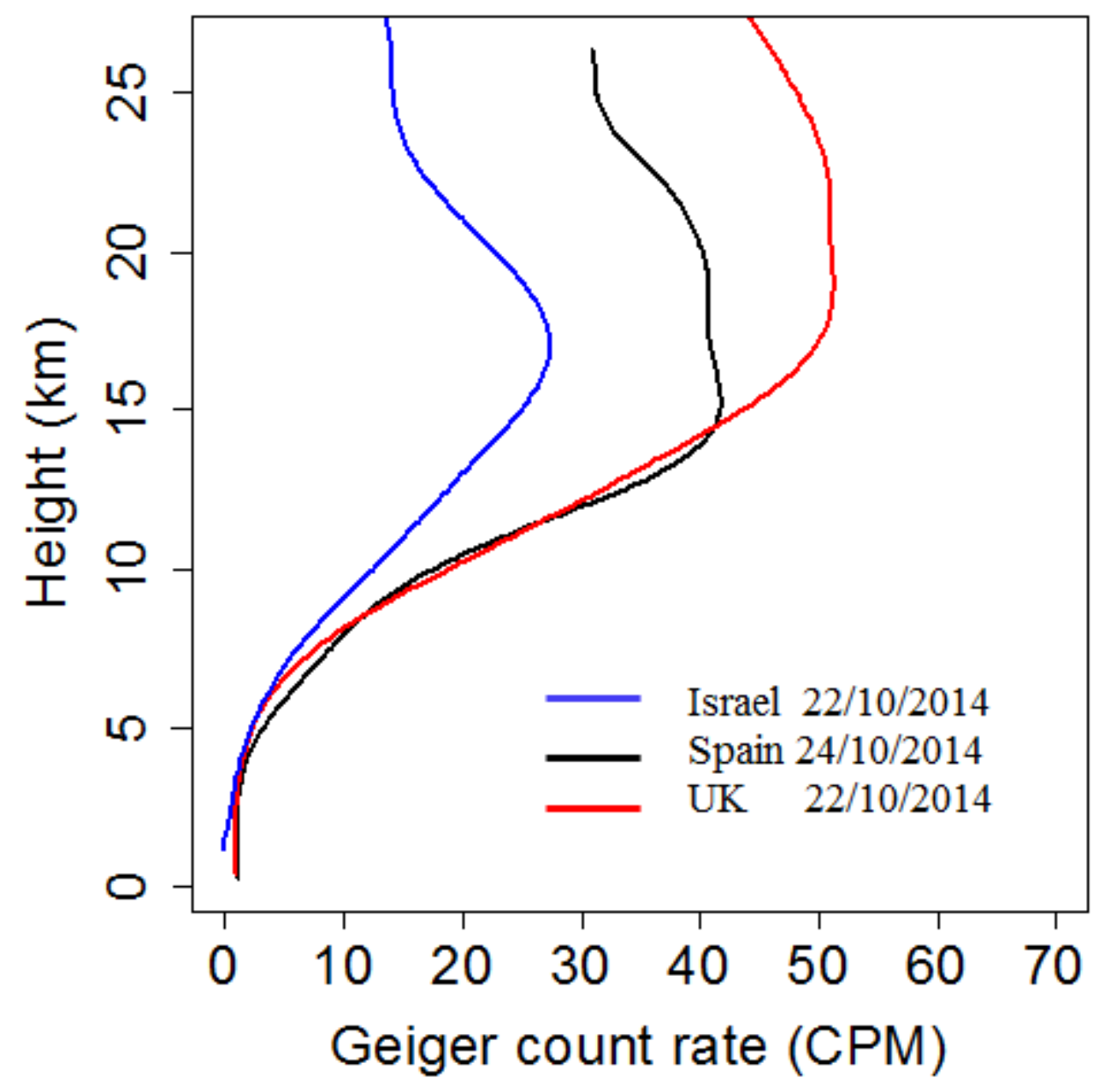

390

391

392

393

394

395

396

397

398

399 
Figure 7:

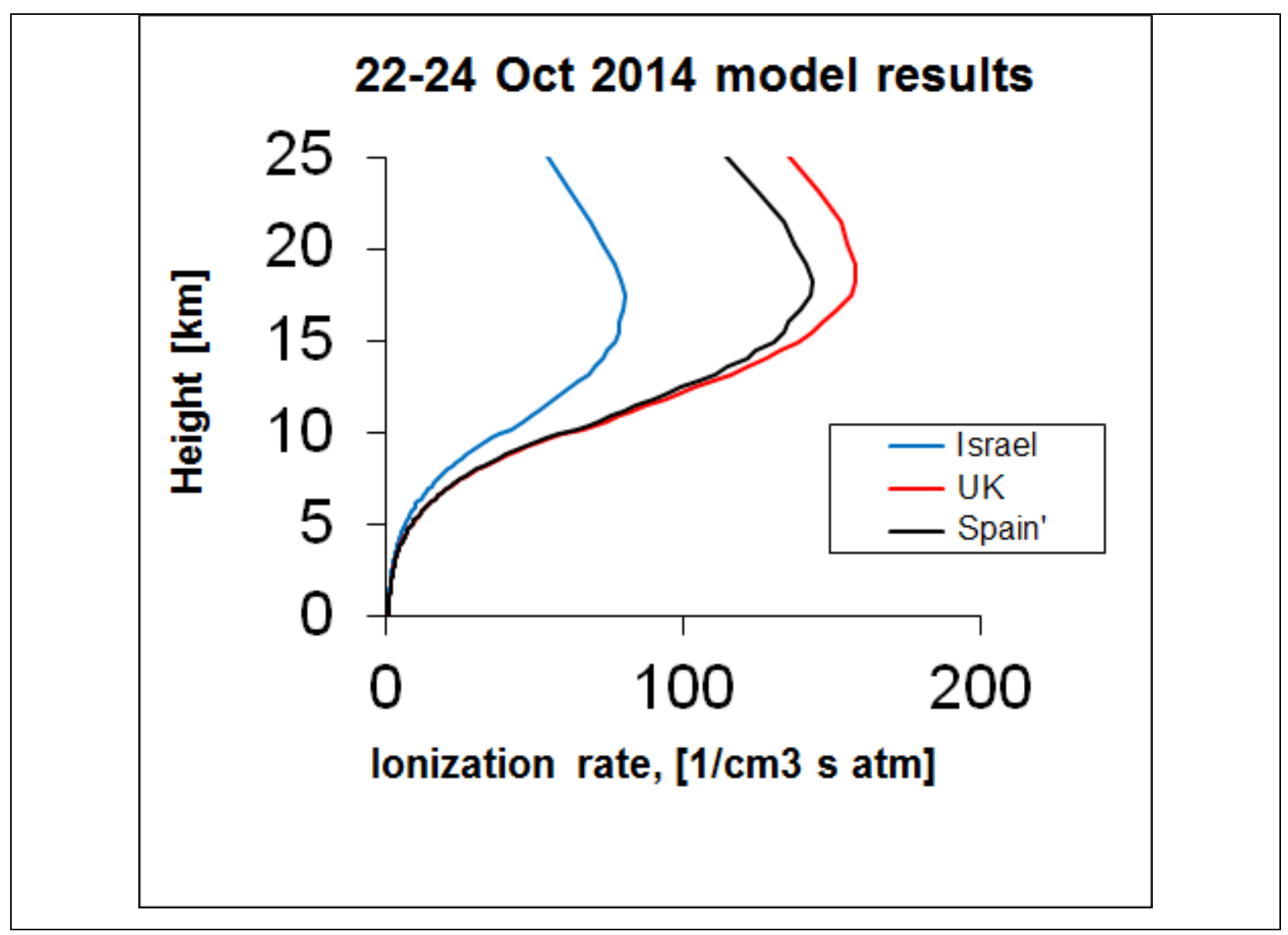

401

402

403

404

405

406

407

408

409

410

411 Figure 8: 

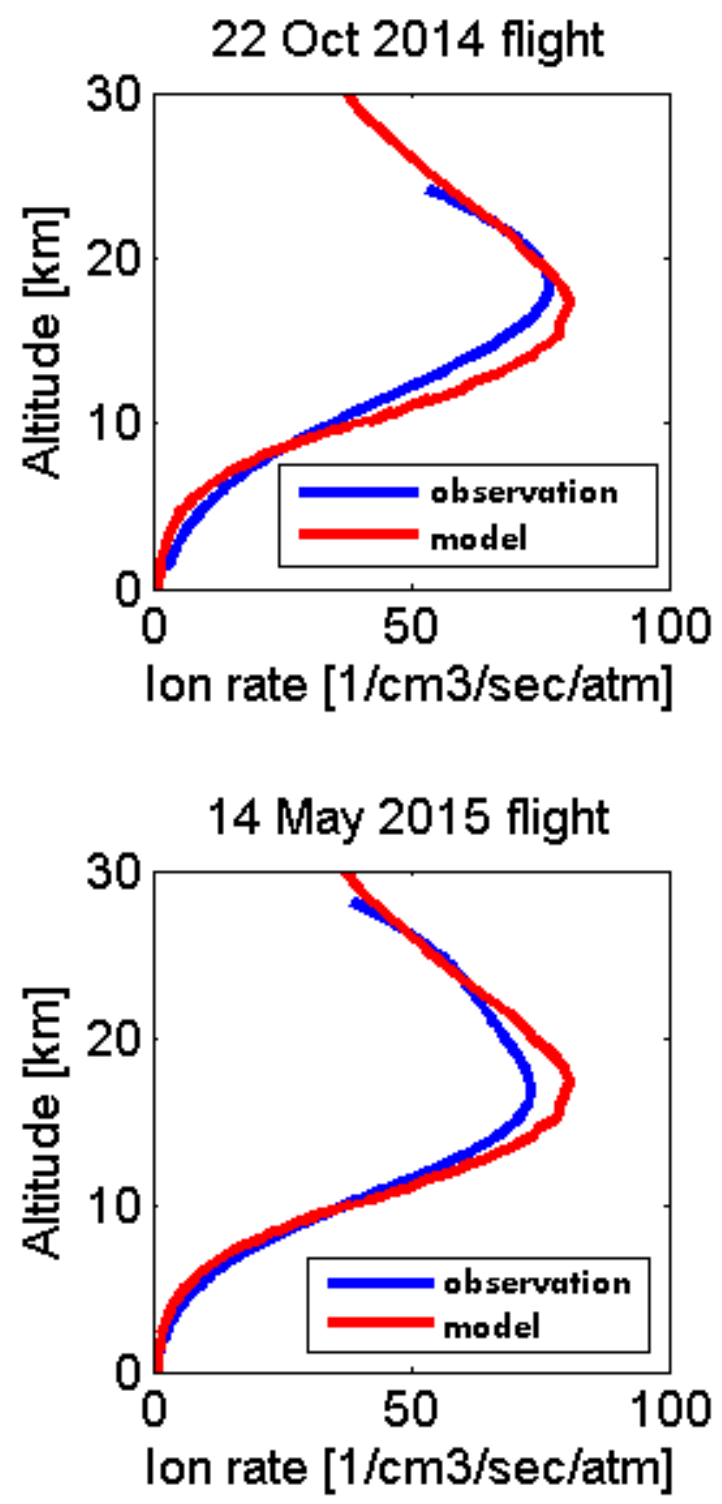

412

413 